\title{
Linx
}

Revue des linguistes de l'université Paris X Nanterre

$41 \mid 1999$

L'hypothétique

\section{Maurice PERGNIER, Du sémantique au poétique avec Baudelaire, Cocteau, Magritte}

L'Harmattan, coll. « Sémantiques », 1997, 128 p.

\section{Jean-Luc Michel}

\section{CpenEdition}

\section{Journals}

Édition électronique

URL : http://journals.openedition.org/linx/815

DOI : $10.4000 /$ linx. 815

ISSN : 2118-9692

\section{Éditeur}

Presses universitaires de Paris Nanterre

Édition imprimée

Date de publication : 1 décembre 1999

Pagination : 167-168

ISBN : 0246-8743

ISSN : 0246-8743

\section{Référence électronique}

Jean-Luc Michel, « Maurice PERGNIER, Du sémantique au poétique avec Baudelaire, Cocteau, Magritte », Linx [En ligne], 41 | 1999, mis en ligne le 27 août 2012, consulté le 22 septembre 2020. URL : http:// journals.openedition.org/linx/815; DOI : https://doi.org/10.4000/linx.815

Ce document a été généré automatiquement le 22 septembre 2020.

Département de Sciences du langage, Université Paris Ouest 


\section{Maurice PERGNIER, Du sémantique au poétique avec Baudelaire, Cocteau, Magritte}

L'Harmattan, coll. « Sémantiques », 1997, 128 p.

Jean-Luc Michel

\section{RÉFÉRENCE}

Maurice PERGNIER, Du sémantique au poétique avec Baudelaire, Cocteau, Magritte, L'Harmattan, coll. « Sémantiques », 1997, 128 p.

1 Cet ouvrage de Maurice Pergnier aurait pu avoir pour titre Défense et illustration de la polysémie. En effet, il s'agit ici, au travers d'études d'œuvres poétiques et picturales, Moesta et errabunda de Baudelaire, L'Hôtel et Blason-Oracle de Cocteau et La grande famille de Magritte - de montrer que l'attention portée à la polyvalence sémantique peut amener à l'interprétation et à la compréhension d'objets esthétiques, et, plus largement, que la polysémie, loin d'être un «accident» du langage, «y remplit une fonction indispensable et centrale ».

2 Deux axes orientent cette étude : la " défense », d'une part et "l'illustration », d'autre part, de la polysémie.

3 En effet, la polysémie est envisagée de façon théorique dans l'avant-propos et dans la deuxième partie du livre, Le signe équivoque. Dans l'un comme dans l'autre, Maurice Pergnier s'attache à préciser le statut linguistique de la polysémie, en ce sens qu'elle appartient au domaine de la langue, et n'est en rien une déviance par rapport à une idéale univocité du signe qui serait considérée comme normale. À ce titre, la polysémie peut devenir un outil de l'analyse du langage poétique, et plus généralement artistique. 

parties du texte, appliquant à l'interprétation de trois poèmes et d'un tableau les idées développées dans les chapitres évoqués plus haut. l'adjectif vert dans le vers célèbre Mais le vert paradis des amours enfantines. Cet adjectif est considéré du point de vue des réseaux de sens qu'il détermine et crée, autant sous l'angle de la syntaxe et de la lexicologie que de la versification. Si M. Pergnier se montre convaincant dans les deux premiers domaines, son analyse des réseaux enfantés par la versification, tout en développant des pistes intéressantes, semble moins efficace: pourquoi, par exemple, dire de vaste dans le poème qu'il est un monosyllabe, alors que la coupe enjambante oblige à réaliser ses deux syllabes ([ ... ] vas/te/mer [ ... ]) ? Toujours est-il que les conclusions que l'auteur tire de cette analyse concernant l'interprétation demeurent discutables, n'épuisant pas le sens qu'on pourrait donner à cette « couleur du paradis », et rendant ainsi grâce à la polysémie...

Par l'analyse rigoureuse et progressive - passant chaque fois du sens le plus «superficiel » au sens le moins évident, requérant le plus de compétences linguistiques et culturelles des deux poèmes de Cocteau, tous deux bâtis sur des jeux d'homonymies complexes, l'auteur étend l'interprétation à l'ensemble du texte, interrogeant les rapports qu'entretiennent entre elles les différentes strates sémantiques des œuvres considérées. Il passe ainsi de l'aspect ludique du poème à son aspect poétique et symbolique, voire biographique, et en vient à établir que la polysémie peut concerner non seulement le mot, mais l'objet esthétique dans sa globalité ; c'est alors tout le poème qui devient polysémique, et $\mathrm{M}$. Pergnier, dans le cas précis d'Opéra d'où sont tirés L'Hôtel et Blason-oracle, parvient à montrer que la polysémie structure le recueil dans son ensemble, et que l'équivoque sémantique en est une des clés fondamentales.

Procédant alors à une ouverture supplémentaire, M. Pergnier achève son ouvrage sur la reprise d'un article paru en 1977 dans La Voix du regard, concernant un tableau de Magritte, et illustrant l'idée que dans un objet d'art, quel que soit le langage utilisé, l'étude de la polyvalence des signes et sa prise en compte permettent de rendre compte de la profondeur de sa signification et d'en affiner la compréhension, sans pour autant en épuiser le mystère.

On a donc affaire à un ouvrage progressif et clair qui joint à l'aspect théorique de son propos («défense» de la polysémie) une mise en pratique d'idées intéressantes et opératoires («illustration») à travers des études ouvertes et laissant place à la discussion, de même que la polysémie laisse ouverte l'interprétation du signe en contexte, notamment artistique. 